\author{
MARTA SongIN-MoKrZAN ${ }^{1}$ \\ Institute of Ethnology and Cultural Anthropology University of Łódź
}

\title{
Transnational entrepreneurship in the context of a globally oriented company located in south-western Poland: A multiscalar approach
}

The article focuses on selected aspects of transnational entrepreneurship, understood in terms of actions that go beyond national borders and lead to long-lasting innovations in sociotechnical spaces. These considerations rest on the ethnographic research conducted in years 2013-2016 in a globally oriented company situated in south-western Poland. While exploring the issue, the author moves between different scales of analysis: from the macro-level of the postsocialist state, through the global infrastructure of neoliberal politics, to the specific working environment and the regional context. The adopted strategy of shifting perspectives is applied in order to point to the larger political, historical and economic contexts in which specific places are embedded and which influence the trajectories of lives of employees of global enterprises.

Keywords: transnational entrepreneurship, Special Economic Zone, global company, ethnographic research.

\section{Introduction}

Social sciences use the concept of transnationalism to describe various social, political, economic and cultural processes that develop not within a nation state, but beyond its borders. It gained particular interest in the 1990s when globalization

${ }^{1}$ Contact: Marta Songin-Mokrzan, marta.songin@uni.lodz.pl 
became intense as a result of neoliberal politics and significant technological advancement in communication. Transnationalism is a valuable conceptual tool of analysis in such fields of studies where the researched phenomena proliferate not within national "container societies", but span in between or beyond them; for example, in the studies of contemporary international migration (Basch, Glick Schiller, Blanc-Szanton 1992; Faist 2000) where it accounts for new immigrant identities and communities (Dolby, Cornbleth 2001). Guarnizo 1997), as well as in the analysis of nongovernmental organizations (Tarrow 2005), corporations and the global networks they establish (Yeung Wai-Chung 2005).

The goal of the article is to point to some aspects of transnational entrepreneurship pursued by a globally oriented company situated in south-western Poland. Firstly, I will focus on the selected elements of infrastructure, understood in a broad sense not only as a material network, but as any system which triggers social action (see Leigh Star 1999), that the postsocialist country undergoing economic transformation built to establish connections with the global economy. Secondly, I will demonstrate certain features of transnational entrepreneurship pursued within a factory that operates within a corporation of European origins. In the presented perspective, "entrepreneurship" is not defined narrowly as a "purposive action leading to the creation of new formal organizations" but more broadly in terms of "any effort to introduce durable innovations in routines, technologies, organizational forms, or social institutions" (Ruef, Lounsbury 2007: 1-2). I am particularly interested in the way a factory situated in a certain local context creates and maintains transnational social spaces as means of efficient and productive work. What is more, the employees in a transnational environment are encouraged to become entrepreneurs of the self, flexible and accountable agents: pursuing their goals by weighing the benefits and costs attached to their everyday activities. In this part of the article I will also indicate the role of non-humans in establishing transnational networks of liability. Thirdly, I will turn to the mobilities, both regional and transnational, as specific forms of entrepreneurial practices of social actors influenced by global factories.

In addressing the highlighted issues I will move between different scales of analysis. My starting point of departure is the view from the macro-level of the postsocialist state and its politics of reconnecting with the West that indirectly encouraged the company, in which I did the research, to chose the investment site. Further, I expand the scope of analysis in order to look at the Special Economic Zones (SEZs) as infrastructures of neoliberal politics that encourage transnational entrepreneurs to establish their businesses in different parts of the globe and facilitate the movement of international capital. The next step is an adoption of the micro perspective to present the working environment of the corporate employees. Here, I focus on the practices of making transnational networks and on the results they bring. Finally, I turn my gaze to the region where the factory of my interest is located. This lub manoeuvre $\mathrm{w}$ BrE helps to understand the trajectories 
of local workers' mobilities influenced by the appearance in the commune of the large-scale infrastructure projects. The strategy of shifting perspectives enables to move between various scales of analysis in order to point to the broader political, historical and economic contexts in which the particular localities and trajectories of workers' lives (both migrant and non-migrant) are embedded.

\section{The research site and methodology}

My conclusions and observations are based on the ethnographic research I conducted between 2013 and 2016. The project Special Economic Zone as a realization of the 'neoliberal imaginary', was dedicated to exploring one of the Special Economic Zones (SEZs) situated within the Lower Silesia region in Poland ${ }^{3}$. I was interested in the spatial layout of the zone, its infrastructure, its perception by local residents and in its impact on the local community, as well as the legal, political and media-related aspects of its functioning. The aim of this research was to analyse in what ways neoliberalism - understood as a mobile technology (Ong 2007) - is introduced, negotiated and implemented within the local context.

One of the goals of the project was to pursue participant observation in the companies located within the Special Economic Zone. At the beginning, I envisaged to study four various factories with distinct corporation cultures, however due to the difficulties with gaining access to the field sites, I eventually decided to stay in the first site, in which I was allowed to conduct the research. I spent there eighteen months (between April 2014 and October 2016), working as a trainee (unpaid internship) at the Planning and Material Resources Procurement Department. My duties included the handling of claims of the materials delivered to the factory. On a daily basis, I completed the data in a special application, emailing with the suppliers and sending samples of the defective material. In addition, I attended various meetings, observed the work practices of office workers, engineers, laboratory workers and production workers. The work in the company gave me a unique possibility to experience the specificities of the corporate daily challenges, to observe habitual performance of the employees and to learn indigenous norms, values and language. I also observed management methods and gained knowledge about the enigma of material production.

Apart from using participant observation, the research was also based on interviews with workers (working at the various companies located in the zone), officials, local authorities and the residents of the commune that hosts the SEZ, as well as on analysing various documents and discourses on SEZs in Poland. The

2 This research project has been funded by the National Science Centre in Poland within the framework of a postdoctoral grant award based on decision no. DEC-2013/08/S/HS3/00271.

${ }^{3}$ In order not to disclose the identities of my interlocutors I decided not to provide detailed information about the SEZ nor the companies of my interest. 
data I am presenting here are also a result of informal conversations held with co-workers. I attempted to gather diverse voices and perspectives of social actors whose lives were somehow reshaped, redirected or influenced by the appearance of the SEZ in the region. The problem of transnational entrepreneurship was not the theme of my interest within the project. However, in the light of the gathered data it is worth reflecting on the issue and subject it to further, thorough examination in the future. Therefore, the article offers preliminary observations and is targeted toward opening lines of argument on the topic.

\section{Connecting to the global economy: A case of postsocialist Poland}

The company of my interest decided to open the factory in Poland in 2008. At that time the country was undergoing a systemic transformation: from central planning to free market. It had already managed to build sufficient infrastructure, the purpose of which was to create and maintain connections with the global economy. As the example shows, the plant was installed in a newly established Subzone (2005), a part of one of the 14 Special Economic Zones operating in Poland since 1995. In a place that had been isolated from the Western market for over four decades, these sites of economic activity were to provide recognizable and reliable investment areas for foreign entrepreneurs, to ease the flow of global capital and knowledge, and to build foundations for multidirectional mobilities of people, materials, machines, compounds and products.

Before I turn to the entrepreneurial practices in the transnational spaces of the global company, in the following section I would like to take a closer look on the nearest surroundings of the factory and to reflect shortly on the role of the SEZs in the process of constituting the environment for transnational networks.

\section{Special Economic Zones in Poland}

Special Economic Zones are separate areas located in state territories, where entrepreneurs conduct business activity under preferential conditions. In the case of Poland they are defined in the Act on Special Economic Zones of 20 October 1994 (Journal of Laws of 2007, no. 42, item 274, Journal of Laws of 2008, no. 118, item 746). According to law an investor may expect to receive: exemption from income tax and, in some districts, exemption from property tax as well, a site to develop the investment provided with all the necessary infrastructure at a competitive price, and also free assistance in all arrangements related to the investment ${ }^{4}$.

\footnotetext{
${ }^{4}$ Available at: http://www.paih.gov.pl/investment_support/investment_incentives_in_SEZ [Accessed: 10.10.2017].
} 
The very nature of SEZ is very complex as its space is territorized and deterritorized at the same time. On the one hand, it is an investment area, usually located in a separate, uninhabited part of the country; a territory carved from local landscape, a piece of land with clearly determined boundaries whose geographic location can be easily found. On the other hand, this tangible aspect of SEZ existence is diminished by the fact that it is predominantly a legal mechanism, hence an immaterial instrument, introduced to stimulate economic growth. It is improved land for an investment, but an entrepreneur may built a factory within its borders and, at the same time, resign from all other benefits (and responsibilities) it offers.

Special Economic Zones emerged in Poland as a result of the transition processes that brought about changes for many families, particularly those whose members were employed in large production plants or coal mines - these industries were either taken over by private business owners or closed down in the 1990s. To mitigate the consequences of the shock doctrine introduced by the neoliberals and to reduce the growing unemployment rate, the successive Polish governments pursued an active policy oriented at attracting foreign entrepreneurs to invest their capital in Poland. Other discursive justifications of these actions included: the necessity to stimulate economic growth and accelerate regional development and the deployment of Western modes of management as well as Western economic knowledge and practices. The goal behind establishing SEZs in Poland was also to manage post-industrial property and infrastructure, to encourage regional cooperation with local organizations and to provide foundations for the development of transnational networks on an unprecedented scale ${ }^{5}$ as well as following the then recent political trend toward economic neoliberalisation.

As a result of introducing legal instruments and mechanisms aimed at offering investment incentives, the first Special Economic Zone was established in 1995. Since then, Poland has opened another 13 Zones, which cover a total territory of over $160,000 \mathrm{~km} 2$. Although they were initially thought out as a temporary tool of stimulating economic growth and predicted to run for 20 years, changes in law regulations first prolonged their existence until the end of 2026 (fourteen regulations of the Council of Ministers adopted on July 23, 2013) and more recently, in 2018, extended the rules applicable in the Special Economic Zones on the territory of the whole country.

Special Economic Zones, although offering the same incentives for both local and foreign investors, were appreciated mostly by global corporations. Since 1995, they have attracted hundreds of multinational companies which brought resources, capital, workers and various types of corporate cultures with them. SEZs are therefore enclaves valuable for making comparisons between different organizational

${ }^{5}$ It has to be underlined that although various systems of transnational connections also functioned in the Eastern Bloc, they were different forms of arrangements and mutual relations. 
structures. They can be viewed as laboratories for testing the functioning of the free market mechanisms ${ }^{6}$, especially in countries undergoing major political and economic transformations. One characteristic feature of SEZs, stemming from their neoliberal genealogy, is that they are grounded locally and globally at the same time. The corporations installed within these territories not only have a significant impact on the region and the state, but at the same time are focused on constituting and maintaining transnational networks.

\section{Special Economic Zones from a global perspective}

Special Economic Zones are not only typical of Poland. They were established in various parts of the world as a consequence of enhanced globalization processes. Therefore, they can be seen as enclaves that enable the international expansion of capital. Although known earlier, Special Economic Zones proliferated within the political and economic environment of neoliberalism oriented toward introducing free-market restructuring projects that were developed in the Western countries following the crisis of John Maynard Keynes's well-fare state model. Neoliberalism, as a radical version of capitalism, rationalises and legitimises activities designed to remove the obstacles to the free movement of international capital, as well as activities aimed at interconnecting local financial markets and creating global networks of mutual interdependencies coupled with supranational trade system.

Special Economic Zones epitomize the essence of the neoliberal economy, oriented toward unrestricted movement of the capital and commodities, as they constitute "clearly delimited and enclosed areas of a national customs territory, often at an advantageous geographical location (Madani, 1999) with an infrastructure suited to the conduct of trade and industrial operations and subject to the principle of customs and fiscal segregation." (UN ESCAP 2005: 6). Special Economic Zones are therefore spaces of "neoliberal exceptions" (Ong 2006); specific "spatio-judical enclosures" (Palan 2003: 1), where particular regulations - which are in force outside the zone - become suspended. Needless to say, in the globalizing world they are just one example of offshore enclaves among many others, such as: convenience states, offshore gambling, offshore finance markets, offshore cyber spaces (Palan 2003: 2, Urry 2014).

With the processes of accelerated neoliberalisation, accompanied and enabled by technological innovations, corporations - as expressed by Henry Yeung WaiChung - "developed into dense spiders' webs and highly sophisticated networks of cross-border operations" (Yeung Wai-Chung 2005: 1). Large enterprises adapted to the new conditions by developing organisational and managerial strategies that

\footnotetext{
${ }^{6}$ I owe this idea to Maria Nawojczyk.
} 
"have enabled them to transcend national boundaries and establish themselves in every corner of the global economy" (Yeung Wai-Chung 2005: 1). Since then, the transnational networks have become the prevailing instrument helping to make connections between distant sites, to regulate, manage and arrange the flows of capital, workers, materials, products and means of production. The entrepreneurial practices of globally oriented companies are focused to a large extent on maintaining and strengthening the infrastructure that connects localities to multiple sites in various parts of the globe.

It also needs to be underlined that these transnational economic networks and the transactions they enable, as Saskia Sassen notes, are not impersonal, but always embedded in social domain (1998). Therefore, various locations are integrated not only through the circulation of commodities, the transfer of capital and technologies, but also through social interactions and shared and negotiated symbolic systems. Therefore, the networks established as a consequence of the multilocality of the companies, searching for new markets, constitute the foundations for transnational social spaces, understood as certain "social realities and entities" (Pries 2003: 3) that are formed, maintained, negotiated and transformed within the 'ergosystems' ${ }^{\text {' }}$ of globally oriented business companies. As Ludger Pries indicates, they are "dense, stable, pluri-local and institutionalized frameworks composed of material artifacts, the social practices of everyday life, as well as systems of symbolic representation that are structured by and structure human life (Pries 2003: 8). In the next section of the article I will take a closer look at the elements that form the transnational social space within the researched company.

\section{Inside the company}

The company is one of the ten globally oriented factories which produce labelling material. The plants are interlinked through various means and obligations; each unit in the corporation has its own patterns of transnational communication. The employers at the Planning and Material Resources Procurement Department where I worked are people of diverse nationalities who live in different countries and maintain daily communication through computer programs, e-mails and communicators. Co-workers usually exchange information not in direct conversations but through the online media, with data entered, stored, exchanged and processed in the cyber space by people and machines. Teams hold teleconferences every

${ }^{7}$ Ergosystem (érgon: 'work' from Acient Greek) refers directly to the notion of an ecosystem that can be roughly defined as a dynamic combination of living organisms and inanimate objects connected by various relations of energy flows and matter circulation. By the same token, I approach 'ergosystem' as the sort of the working environment built upon the network of dependencies, relations and negotiations, which include both humans and non-humans. 
morning and stay in touch throughout the day if needed. From time to time, team members meet face to face during workshops followed by informal meetings in the evening. Such a structure, which even allows to remotely substitute a co-worker from another country, is based on multifocal transborder connections and affects the way workspace and social relations are built.

The position I held gave me the opportunity to experience different forms of contact with co-workers of various nationalities. From direct meetings to most elusive communication with an Indian IT specialist, who remotely changed settings on my notebook (after granting him permission to enter my computer by clicking on a pop-up window I only sat and followed the cursor movements on the screen, while the person whom I have never seen or talked to before was changing the system's configuration). As the example shows, the medium that connects people's activities is an extensive information and IT infrastructure which includes sensors, programs and computer networks that create a coherent communication system, control the work of machines and people, collect data and partially analyse it. This means that the network controls the machines and controls and disciplines the employees. The way the company is structured results in in the deterritorization of workspace a workspace which is constituted of various kinds of local and transborder linkages. The workplace and the workspace do not entirely overlap. While the workplace is materially grounded, the workspace constitutes a more complex arena of various kinds of obligations to clients, co-workers, suppliers, company values and standards.

The components of the discussed 'ergosystem' which play a key role in producing a transnational corporate space are not only means of communication but also management methods based on Lean Management, Six Sigma, Total Quality Management, ISO certificates, procedures and instructions, health and safety at work regulations, knowledge of machines and exact science technologies. They influence the way the production process and employee relations are organized and also set supranational standards and norms.

It can be said that the functioning of the whole factory, that is the structure and methods of work, communication, actions taken by employees, production model, material storage system and finished products, methods of planning or quality control are to a large extent structured based on, firstly, modern management methods rooted in the Japanese model (which, to put it simply, rely on the use of tools allowing for maximum efficiency and productivity of people and machines while eliminating waste and all kinds of wastage in time, activities or materials, etc.). In order to achieve the best results, the performance of workers and machines is constantly monitored and transcribed into data of various kinds. Indicators that measure the activities of people and machines are compared globally between sites in different countries. The outcome of such comparisons influences future strategies adopted by managers. In order to meet their targets, set annually on a global level, employees, with the inextricable participation of machines, software and IT 
networks, constantly monitor their own activities and watch over the implementation of the locally adopted goals.

With the application of the of auto-auditing practices, workers become the "entrepreneurs of the self, engaged in self-interested conduct as personal investment" (Dilts 2011: 139). According to Michel Foucault $(2008,2009)$, this endeavor is part of the broader processes embedded in the neoliberal ideologies of the contemporary. As indicated by Nikolas Rose, fundamental to the neoliberal imaginary is a desire to "govern from a distance" (Rose 2010: 49). Andrew Kipnis notices: "governing from a distance involves both spatial and 'constitutional' distance: constitutional in the sense that the intervention into the lives of the governed should be carried out by means other than direct intervention by an agent (...). For example, rather than directly issuing commands to subjects, governing agents attempt to shape structures of economic inducement that will lead to the desired behavior" (Kipnis 2008: 279). In global companies the crafting of neoliberal identities is pursued with the help of non-humans: machines and IT technologies. And, as the workers' performance is compared on a global scale, the entrepreneurial self emerges as the product of a relation with the imaginary elsewhere.

Equally important are ISO standards (i.e. set by the International Organization for Standardization, which deals with introducing standards in all areas of our lives). As Elisabeth Dunn (2005) argues, companies choose to acquire a variety of certifications and use certain management methods to be identified or defined by potential customers as responsible and credible business partners. These practices enable them to connect to global networks, where the exchange of commodities and services takes place (as pointed out by Dunn (2005), the necessity to appoint certain standards defined at supranational level, by various institutions and organizations, leads to the exclusion of the smaller entrepreneurs who produce the goods on a local scale).

To maintain ISO certificates, companies must meet certain standards that largely regulate employee practices and produce enormous amounts of data that, like employee knowledge, can be evaluated during mandatory, periodic audits. Moreover, standards and audits have a significant impact on the behaviour of the workers. The unification and standardization of the 'ergosystem' requires the introduction of innumerable instructional and disciplinary practices regulating the operations of social actors, whose main task is to manage themselves effectively.

Companies situated in different locations are deeply interconnected with regard to safety measures. If there is an incident or an accident in one of the locations, all workers are informed about it and are obliged to introduce safety procedures in order to avoid a similar occurrence in their country (even if they do not find the solutions necessary and meaningful). This demonstrates that transnational social spaces establish a framework of mutual liability. Everyday performance of workers is to a large extent determined by these interdependencies. The corporations 
tend to set standards regarding material and non-material spaces in order to create a common platform, where companies and the performance of their employees can be measured and compared.

Such environment favours considering one's own position not only in relation to the closest co-workers but also to those working in other countries. It also contributes to the creation of so called "transnational imaginary" (Wilson and Dissanayake (eds.)1996) which gives individuals a ground to project images of distant places they either know or have never visited. The workers who had the possibility to travel to other sites in order to gain experience from their colleagues abroad often compare the working conditions, habits and technological solutions implemented elsewhere. They create visions of the ideal workplace being an amalgam of the various experiences gained here and there.

It is worth worth emphasizing that all workers of the researched company to some extent participate in the transnational space, regardless of the function and position. All their actions leave cyber traces in the system, where all relevant information about the performance of people and machines is stored. The goals for individual workers and teams are set on the basis of the data and the comparisons made between different sites. However, the lower the position the employee has in the organizational structure, the less evident and more elusive becomes her or his participation in the transnational corporate space. Managers and other white collar workers gain access to means of communication and are entitled to enter data, have knowledge and skills and frequently travel to different sites and create transnational bonds. They also hold multiple online international meetings every day. The higher the rank in the organizational structure of the company the contact with the colleagues from oversees becomes more intensive. Due to this fact workers of the company develop different "transnational imaginaries". Production workers, for instance, are mainly concerned with the working conditions of their counterparts elsewhere. Creating the frame of comparison they imagine the other workplaces as deprived of everyday toil they experience.

The last interesting aspect of building transnational social spaces in the global company is "the extension of the production processes", which to a large extent relies on workers' understanding of machines, science technologies, materials and products. It results in building transnational forms of knowledge shared mutually by suppliers, producers and customers. By using the concept of "the extension of the production processes", I refer to Bruno Latour (1988) who argued that in order for scientific inventions to work, the conditions in which they were brought up to life have to be transferred outside of the laboratory ${ }^{8}$. In the same manner the

${ }^{8}$ Latour called this operation "the extension of the laboratory". The convincing argument he used in order to prove the thesis was the "pasteurization of France" (1988), that is, the process of grafting technologies, standards and procedures developed in laboratory conditions by Louis Pasteur to other "unscientific" contexts. In order for the inventions to work outside the testing rooms, the 
production processes of the laminate are not limited solely to the factory where it is manufactured. The producers stay in contact with the suppliers in order to eliminate defects that appear on the materials from which the laminate is being created. After receiving a claim, a supplier is obliged to perform changes that can help to eliminate recurring defects. From time to time, if the problem continues, the producers and suppliers meet to discuss the issue, to develop new ideas and to negotiate possible adjustments. The extension of the production processes also involves clients. When the clients encounter severe difficulties in using the laminate, representatives of the Quality Department (from the manufacturer's site), visit the contractor's factory in order to help set up the machines in a way ensuring the clients' production processes proceed undisturbed.

\section{Mobilities in different scales}

Workers of the companies installed in the Subzone (the total number of which is estimated at around 10000$)$ constitute of: migrants from various parts of the world, the residents of local and more distant communes, and the citizens of the capital of the region. SEZ is therefore a platform where people from different places and of various nationalities meet, where migrant and non-migrant workers interact. This sphere of contact influences the way people build their transnational imaginaries not only by referring to distant places but also to other cultures. The companies in the Subzone are based on specific organizational cultures and introduce diverse managerial practices, which to a large extent determine the mobility paths of local and international workers.

\section{Transnational paths of white collar workers}

With regards to regards to the top management, the companies of Western origin transfer the employees to other locations for a significant amount of time (usually a few years). These managers lead a nomadic way of live, moving from country to country with their closest family (partner and children) and build various bonds with various places: their state of origin and the place of their current stay. In the case of Asian companies, top level managers are sent to Poland in order to gain experience and build their professional positions. After 3-5 years they go back to their homeland (this is an important step in building their carriers).

\footnotetext{
necessary infrastructure had to be built. One of the most quoted examples of this endeavor was the implementation of the vaccine for anthrax. The medication could be successfully used only after the scientist managed to convince the farmers and the public that the standards of keeping animals have to be changed.
} 
Tools provided and maintained by global companies to enable day-to-day transnational communication do not actually contribute to the escalation of migration of white collar workers from other countries. The possibility to work and control the work of others from practically every part of the world that has access to the Internet allows for some employees to fulfil their tasks remotely. For example, the head of the department I worked in lives in Spain and travels to Poland every month or two. Other managers, as I already mentioned, also frequently move between various localities. During my time at the company, there were only few foreigners working on site (the top management and a few middle-level managers). The firm also provides an opportunity for Polish employees to work abroad. In the factories whose workers I had a chance to interview, the top management comes from the country where the mother company is installed.

\section{Shifting scales again: the region}

In order to address the issue of mobilities of Polish (local as well as migrant) workers influenced by the appearance of foreign factories, in this section I will focus on the locally grounded efforts of building infrastructures for globally oriented investments. The company of my interest, as mentioned before, was built in one of the Subzones managed by the Industrial Development Agency, Joint Stock Company, wholly owned by the State Treasury, located in south-western Poland. Other factories based in the area are primarily owned by Asian capital. There are also several companies managed by European investors. The Subzone, in turn, is installed within a commune that prior to the economic transformation process started in 1989 was a typical agricultural region, where $50 \%$ of the land was accumulated within the state-owned collective farms (PGR) which employed several hundred workers. There were also a few small factories in various villages, but they did not have any substantial impact on the local economy.

In the early nineteen-nineties local authorities decided to transform the agricultural commune into an agricultural and industrial one by diversifying the processes of production and by creating conditions for the development of large industrial, logistics, and trade investments. The goal was to create and maintain the potential of attractiveness of this area by building investment-friendly infrastructure. Therefore, the authorities at that time developed various strategies to make the region recognizable and intelligible to foreign entrepreneurs, or in other words, to make it materially and symbolically available. This involved redefining the commune's lands through various practices.

These efforts resulted in building many large-scale infrastructure projects such as the already mentioned Subzone - and although agriculture remains an important element of the local landscape (as $85 \%$ of the commune's lands are 
very high-quality cultivated lands), the investments have profoundly changed the profile of the commune. Large-scale infrastructure projects radically transformed and reorganized the local landscape also because their presence brought about an increase in the commune's budget which has been earmarked for building public utility facilities, such as schools and healthcare institutions, sports and community centres, and for infrastructure development: new roads, pavements, sewage systems etc. It has to be underlined that local municipal, along with two different state agencies, is an active actor involved in the process of establishing the Subzone. It is responsible for maintaining the material infrastructure (roads, media supply) and, in return, it collects property tax (from which the companies from the zone are exempt for the first five years), which is its main (but not the only) source of income.

The strategy for enhancing local development placed the region in the top ten individual municipalities as regards income tax ratios per capita. This, in turn, initiated the movement of people and various forms of mobility observable on a micro, local and global scale. The commune offers an extensive range of social facilities for its residents and is therefore often selected as a place to live by the representatives of middle and upper-middle class from a nearby city, which is the capital of the region. The status of one of the richest communes in Poland, as reported to me by local mayors, attracted inhabitants of other provinces as well. These people came here in search of work and decided to settle in the area.

What is more interesting, although the large infrastructure projects were to foster local employment, the original inhabitants of the commune rarely choose the new enterprises as their preferred workplace. When I was searching for interlocutors in the nearest surroundings of the zone, I discovered that only a few decided to find employment at the local factories. Later in the interviews, numerous residents of the commune reported that the local people have a range of choices regarding workplace and the SEZ is not considered by them as the most attractive one. On the contrary, it acquired a rather unflattering nickname, as some refer to the SEZ in terms of a "humanitarian concentration camp". Therefore a majority of workers of the Subzone are recruited from various villages and towns spread in the entire voivodeship, where the rate of unemployment is much higher. Some companies arrange their own, free of charge means of transportation to provide commuting for workers from the most distant parts of the region (the longest route takes up to two hours one way).

\section{Moving between companies}

In the Subzone most of the production workers are mostly recruited from mostly from people of Polish nationality. In the last four years an interesting change has been observed in relation to the gradually increasing diversity in the nationalities of the production workforce in Asian factories located in the Subzone. 
In order to sketch the broader context of the phenomena, we need to go back to the 1990s where Poland's transition to democracy began. For the commune where the Subzone is located, it was a moment when over a very short period of time, the legitimized practices of management, and various types of economic activities that had been in operation for several decades, proved to be obsolete; the skills of workers of the state-owned collective farms lost their value virtually overnight. It was one of the reasons why the region became an attractive investment area for factories, as later this group of people was to be described as unqualified workforce and formed a large proportion of the production workers employed in the Subzone companies. In the bulletin published in 2009 , addressed to foreign investors and dedicated to polish SEZs, experts still argued that Poland "offers some of the lowest labor costs in Europe (average monthly remuneration is about EUR 750) and a highly qualified, young labor force" (KPMG 2009: 9).

Nevertheless, the situation has changed over the years. Interest in the production work offered by the companies situated in the Subzone decreases, especially in young people. The rotation of workers is high, and recruitment is ongoing. In the interviews, I was told stories of young people who stayed in the factory for a few hours only to never show up back at work after the lunch break. They would leave without informing anyone about their decision. This attitude towards work is most probably connected with the wide range of job opportunities in the area. The young production workers I interviewed often compare between different companies, discussing the working conditions, wages, the attitude of the management etc.

Inhabitants of the region, mostly young people in their twenties and thirties, usually move between different corporations within the region. This applies to experienced (managers, top managers) and inexperienced (occupying the lowest positions in the companies, working on production lines) workers alike, who search for promotion opportunities. At the beginning of their carrier paths, people usually try to gain some experience in the factories where no professional knowledge is needed and subsequently move on to looking for more satisfying posts (with higher wages and better working conditions). In the interviews, many acknowledged that the best opportunities for personal development can be found in newly established companies. In such factories, promotion is far more likely than in the firms with already stabilized structure. This example shows that workers of the zone are mobile, calculative, flexible, and change the workplace with ease.

The continuous shortage in production staff coincides with the wave of migrants from Ukraine which has been growing over the last three years. Although it is hard to estimate the exact number of Ukrainians working in the Subzone as the companies do not provide such data, it should be emphasized that they constitute a visible group that attracts the attention of other workers. Their presence in the Subzone has already produced a reaction of Polish trade unions. As one of the representatives of the Solidarność trade union, from one of the Asian companies, 
indicated in the interview, Ukrainian workers show readiness to work after hours and accept lower wages. Usually, they want to spend only a certain amount of time in Poland, save money, and return to their homeland. Trade union members decided to act against the employment of Ukrainians, as they were afraid that their presence will worsen the working conditions for the Polish staff. They decided to convince the general manager that employing their foreign colleagues is not profitable for the company. To provide hard evidence for their alleged unproductiveness, the representatives of Solidarność conducted a study to gather data on the effectiveness of two production lines covered by Polish and Ukrainian workers separately. They presented the study results in a presentation including diagrams and tables - namely statistical evidence proving the disadvantages stemming from employing Ukrainians. Now, as the result of these efforts, that particular Asian company employs only Poles to work on the shop floor.

\section{Conclusion}

In the article I aimed at presenting the idea of transnational entrepreneurship, as a phenomenon which, in order to be well understood, has to be approached from various perspectives and through different scales of analysis. It is connected to changes that occurred in the global economy as early as the nineteen-sixties, followed by the accelerated politics of neoliberalisation in various parts of the world and the rise of new technologies (the development of which, in turn, was stimulated by the needs of international business). I also attempted to address the way the globally oriented companies influence the changes taking place in local contexts, how they encourage the movement of people and stimulate their entrepreneurial skills and attitudes. And, last but not least, I wished to show the intricacies of the everyday struggles of the corporate workers and the elements constituting the transnational networks through which they navigate in order to achieve established goals. As the analysis shows, the ergosystem of the corporation is built upon organizational structures, means of communication, symbolic systems and social relations (which involve human and non-human actors), all of which are constructed and negotiated in the space which includes tangible and localized everyday working practices and a kind of immaterial elsewhere.

\section{References}

Basch, L., Schiller, N. G., Blanc - Szanton C. (1992). Transnationalism: A New Analytic Framework for Understanding Migration, "Annals of the New York Academy of Sciences" 645, s. $1-24$.

Dilts A. (2011), From 'Entrepreneur of the Self' to 'Care of the Self': Neo-liberal Governmentality and Foucault's Ethics, "Foucault Studies", No. 12, s. 130-146. 
Dolby N., Cornbleth C. (2001), Social Identities In Transnational Times, “Discourse: Studies in the Cultural Politics of Education", Vol. 22, No. 3, s. 293-296.

Dunn E. (2005), Standards and Person-Making in East Central Europe, w: Ong A., Collier S. J., |Global Assemblages: Technology, Politics, and Ethics as Anthropological Problems Malden, MA: Blackwell, s. 173-193.

Faist T. (2000), The Volume and Dynamics of International Migration and Transnational Social Spaces, Oxford: Oxford University Press.

Foucault M. (2008), The Birth of Biopolitics: Lectures at the College de France, 1978-1979), trans. G. Burchell. New York: Picador.

Foucault M. (2009), Security, Territory, Population: Lectures at the College de France (1977-1978), trans. G. Burchell. New York: Picador.

Guarnizo L. E. (1997). The Emergence of a Transnational Social Formation and the Mirage of Return Migration among Dominican Transmigrants, "Identities: Global Studies in Culture and Power", Vol. 4, No. 2, s. 281-322.

Kipnis A. (2008), Audit cultures: Neoliberal Governmentality, Socialist Legacy, Or Technologies Of Governing?, "American Ethnologist”, Vol. 35, No. 2, s. 275-289.

KPMG (2009), A Guide to Special Economic Zones in Poland, PIaFIA.

Latour B. (1988), Pasteurization of France, trans. A. Sheridan and J. Law, Cambridge Mass.: Harvard University Press.

Madani D. (1999), A Review of the Role and Impact of Export Processing Zones. Policy Research Working Paper 2238, The World Bank.

Ong A. (2006), Neoliberalism as Exception, Durham, NC: Duke University Press.

Ong A. (2007), Boundary Crossings. Neoliberalism as a Mobile Technology, "Transactions of the Institute of British Geographers", Vol. 32, s. 3-8.

Palan R. (2003), The Offshore World, London: Cornell University Press.

Pries L. (2003), New Transnational Social Spaces: International Migration and Transnational Companies in the Early Twenty-First Century, Taylor \& Francis e-Library.

Ruef M., Lounsbury M. (2007), Introduction: The Sociology Of Entrepreneurship, w: Ruef M., Lounsbury M. (red.) The Sociology of Entrepreneurship (Research in the Sociology of Organizations, Volume 25), Emerald Group Publishing Limited, s.1 - 29.

Rose N. (1999), Powers of Freedom: Reframing Political Thought, New York: Cambridge University Press.

Sassen S. (1998), Globalisation and its Discontents. New York: New York Press.

Star S. L. (1999), The Ethnography of Infrastructure, "American Behavioral Scientist", Vol. 43, No. 3, s. 377-391.

Tarrow S. (2005), The New Transnational Activism, New York City, USA: Cambridge University Press.

UNESCAP (2005), Free Trade Zone and Port Hinterland Development United Nations United Nations, Economic and Social Commission for Asia and the Pacific, New York.

Urry J. (2014), Offshoring, Cambridge: Polity Press.

Wilson R., Dissanayake W. (red.) (1996), Global/Local' Cultural Production and the Transnational Imaginary. Durham: Duke University Press.

Yeung Wai-Chung H. (2005), Transnational Corporations and Business Networks: Hong Kong Firms in the ASEAN Region, Taylor \& Francis e-Library. 